\title{
EXPERIMENTAL INVESTIGATION ON HONEYCOMB COMPOSITE MATERIALS
}

\section{VENU MADHAV GORANTLA \& UPPUTURI HARI BABU}

P. G Student, QIS College of Engineering and Technology, Ongole, Andhra Pradesh, India

Professor, QIS College of Engineering and Technology, Ongole, Andhra Pradesh, India

\begin{abstract}
Honeycomb structures are often natural or artificial assemblies, which have the similar geometrical shape of a honeycomb and are used to get the expected strength by minimize the amount of used material, reduce the weight and cost of the materials. The advantages of honeycomb sandwich structures when compared to conventional structures are that it provides: very low weight, production cost savings, durability and high stiffness. Acrylic Honeycomb structures are made-up of unique core material that offers advantages such as good impact strength, transparency, resistance to breakage, elasticity, good weather ability, good heat resistance,excellent dimensional stability.In this paper Acrylic honeycomb sheet structure is used as a core material along with carbon fiber reinforced polymers (CFRP) and glass fiber reinforced polymers (GFRP) as face sheets for fabricating the honeycomb sandwich composite and evaluate the mechanical properties like tensile strength, flexural strength, impact strength and hardness. Scanning electron microscope (SEM) analysis also conducted for checking the good bonding of the honeycomb structure.

KEYWORDS: Honeycomb, Carbon Fiber, Glass Fiber, Face Sheets, Composite, SEM
\end{abstract}

Received: Jun 09, 2020; Accepted: Jun 29, 2020; Published: Aug 06, 2020; Paper Id.: IJMPERDJUN2020653

\section{INTRODUCTION}

Nowadays, honeycomb sandwich composites materials are interesting areas for the most widely applied fibers in the composite technology. Honeycomb structures are mostly natural or sometimes man-made assemblies that have the geometry of a honeycomb is employed to attenuate the quantity of used material and reduce the weight and cost of the materials. The advantages of honeycomb sandwich structures, when compared to conventional structures, are that it provides: very low weight, production cost savings, durability, and high stiffness. Honeycomb cores find wide applications in sandwich structures where there is primary function is to resist transverse shear loads similar to the web in the I-section beam. Generally, an aluminum honeycomb core is used in applications requiring sandwich construction with Fiber-reinforced composite face sheets. Composite materials, such as glass fiber or carbon fiber reinforced plastics are suited for sandwich construction methods due to their low weight, high stiffness, high strength, dimensional stability, and ease of manufacture. Sandwich panels are used for design and construction of lightweight transportation systems such as satellites, aircraft, missiles, high speed trains and biomedical applications. Komal.A.J and D.P.Kamble [1] have investigated the mechanical properties of honeycomb composites. The honeycomb composite made up of aluminium core with FRP as face sheets. They conduct both bending and impact tests theoretical as well as experimental and finally compare the test results with FEM. M. Bharath Kumar and V. Diwakar Reddy [2] are used square and circular tubes are used as Cores in sandwich panels. Taguchi design of experiments is used for optimizing the parameters like core-gap, face sheet thickness, core shape, core height, and Panel dimensions. They reported that Core-Gap is most influence parameter but the Face sheet thickness is the least influence parameter for both 
bending and maximum shear strength. Satya kiran O.N.V et al. [3] have conducted experiment on three different core shapes, namely C- Core, rectangular core and HAT core. They compared the mechanical tests result with the finite element model. They reported that rectangular core panels have higher compressive strength and also the deformation of rectangular core sandwich panel is lower compared to other shapes. Dipak G. Vamja and G. G. Tejani [4] have selected composite material of Aluminium as skin material and polyethylene as core material for fabricating the composite material. They reported that tensile strength and bending strength with hexagonal composite material is less compared to without hexagonal composite material. F. Ernesto Penado [5] has conducted experiment on composite core and aluminium core as honeycomb and fibers as faces sheet. Finite element analysis also conducted to represent the unit cell. Composite core showed that the transverse shear moduli are always higher than those of aluminum for the same core density. K. Kantha Rao et al. [6] have selected several core shapes such as aluminum, titanium and high tensile steel and material for the construction of sandwich among them, it has been known that the aluminum honeycomb core exhibit excellent mechanical properties with regards to weight savings and fabrication costs. They concluded that the wall thickness of a honeycomb core cell is a critical variable affecting the crushing strength of the sandwich panels subject to lateral pressure loads. Ajinkay R. Bagade and Prashant M. Kulkarni [7] have conducted bending test on the aluminum honeycomb sandwich beam specimen, varying the honeycomb core cell thickness, core cell sizes. They observed that with an increase in the thickness of honeycomb core cell, the start of plastic deformation could be delayed, resulting in increase of ultimate strength. The study reveal that honeycomb panel structural behaviuor is mainly depends on its face sheet thickness and core height $\&$ core thickness. By increasing the thickness and core geometry as in a desirable manner, the flexural strength of the honeycomb panel improves. Shaik.Nazeer and Shaik Allabakshu [8] have considered different types of honeycomb core structures like square, hexagonal, pentagonal, tetrahedral, pyramidal etc in this study. They conduct structural and thermal analysis for square and hexagonal honeycomb structures. Structural analysis is being used to determine the effects of loads on the physical structure. Thermal analysis to calculate the temperature distribution and related thermal quantities in the system or component of the composite materials. They concluded that aluminium honeycomb has less deflection and also less weight and cost comparing to other materials like titanium. Pankaj Goswami [9] has selected Aramid honeycombs because of as ultra-lightweight material, good thermal and fire retardant properties Aluminium honeycomb possess highest strength to weight ratio but due to its corrosive nature it cannot be installed in marine application and building insulation. Hexagonal honeycomb structure of aramid fiber filled its core with silica aerogel to make it mechanical, corrosive as well as thermal resistant for building insulation or like other applications. Md. JabihullaShariff and R. Satya Meher [10] have selected two different core structures like Hexagonal and Rhombus and aluminium as face sheet. They observed that composite material having hexagonal structure weight is less compared with rhombus structure. The weight difference between two structures is small, but tensile strength and bending strength of hexagonal shaped structure is less compared with rhombus shaped structure. From the review of exhaustive literature, it has been found that Acrylic honeycomb composites have not yet addressed anywhere. Many researchers concentrate the studies on honeycomb composites, which are made up of Aluminium or Paper as a core material and glass or carbon as face sheet.

Therefore, in the present study Acrylic polymer is selected as hexagonal shaped honeycomb material, which act as a core material and glass/carbon fiber as a face sheets for fabricating the honeycomb composite. The honeycomb composite has fabricated by the Hand Layup method and finally evaluated the mechanical properties by preparing the samples as per the ASTM standards. 


\section{MATERIALS}

\subsection{Acrylic Sheet}

Acrylic sheet is a combustible thermoplastic material. It observes the fire precautions appropriate for comparable forms of wood and paper products. The features that are making it most preferred in the industry of the composite materials are: excellent appearance, easy repair and simple processing technique.

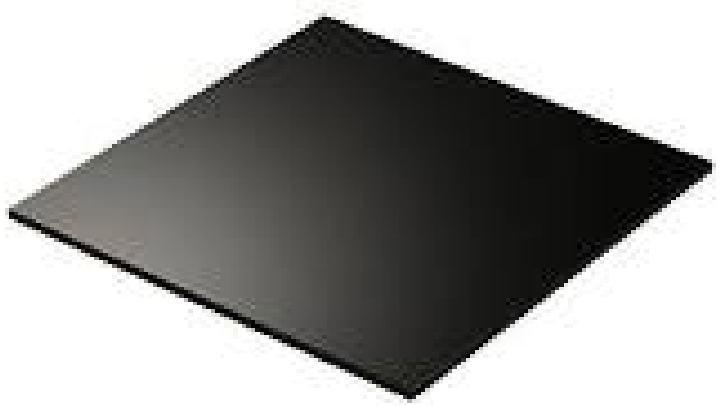

Figure 1: Acrylic Sheet.

\subsection{Glass Fiber}

The composites used today in the industry are made of glass fibers. Fiber glass composite materials exhibit significant reduction within the weight than the composites made from steel. Fiber glass may be a lightweight, extremely strong, and robust material. The material is usually far less brittle, and therefore the raw materials are much less costly. Its bulk strength and weight properties also are very favourable in comparison to metals, and it is often easily formed using moulding processes. Common applications of fiber glass include high performance aircrafts, boats, automobiles, water tanks, roofing and pipes etc.

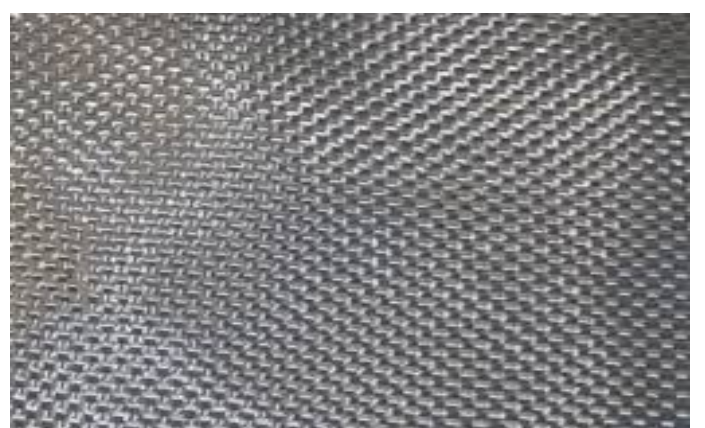

Figure 2: Glass Fiber Reinforced Polymers.

\subsection{Carbon Fiber}

The atoms of carbon are bonded together in microscopic crystals that are more or less aligned parallel to the long axis of the fibers. The crystal alignment makes the fiber sheet very strong based on its size. Several carbon fibers are twisted together to form a yarn, which may be used by itself or woven into a fabric. Carbon fiber has many different weave patterns and can be combined with a plastic resin moulded to form composite materials such as carbon fiber reinforced polymer to provide a high strength to weight ratio material. The density of carbon fiber is additionally considerable less than the density of steel, making it ideal for applications requiring low weight. The cost of the carbon fibers is more compared to other fibers like glass. The properties of carbon fiber like high lastingness, low weight, and low thermal expansion make it very fashionable in aerospace, electronics, military, packaging, sports, construction and automotive industries. 


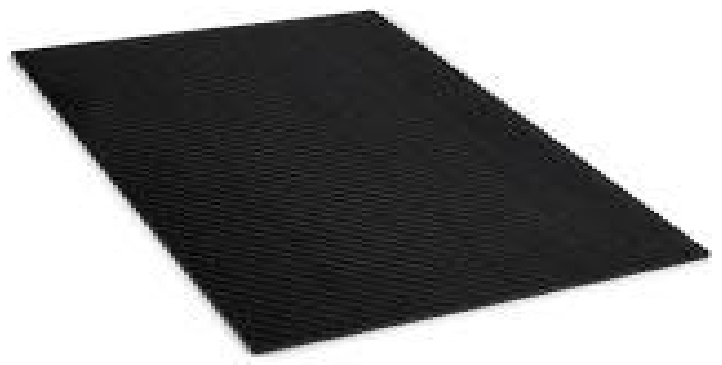

Figure 3: Carbon Fiber Reinforced Polymers.

\subsection{Resin and Hardener}

Epoxy resin is used to give great bonding properties between the fiber layers to form the matrix. The Epoxy resin used at room temperature is LY 556. The epoxy is chosen as the polymer matrix amidst other matrices because of its good mechanical strength, chemical resistance and service temperature requirements. Hardener (HY 951) is employed to improve the interfacial adhesion and impart strength to the composite. Here the resin and hardener mixture of 10:1 is used to obtain optimum matrix composition.

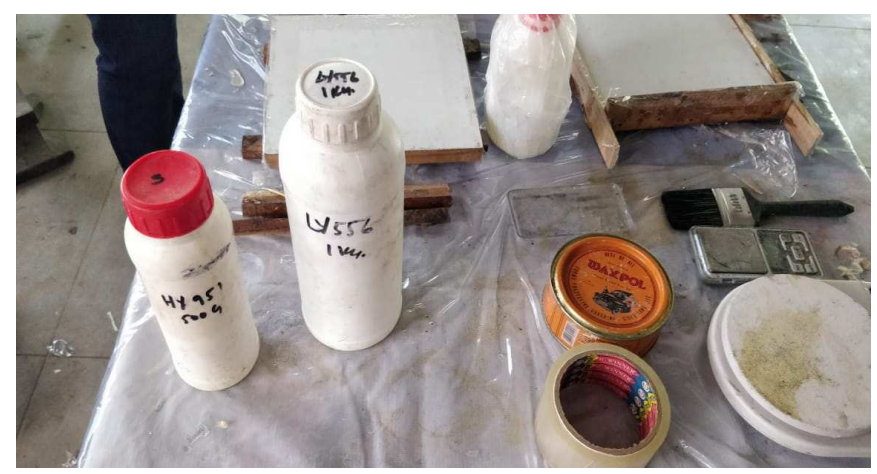

Figure 4: Epoxy Resin and Hardener.

\section{FABRICATION PROCEDURE FOR SPECIMENS}

\subsection{Weights before Fabrication}

- Bidirectional Fibre glass of $420 \mathrm{gsm} \gg 29$ grams

- Bidirectional Fibre carbon fabric of 420 gsm $>28$ grams

- $\quad$ Epoxy araldite LY556 $100 \%$ of layer weight

- Hard nerardur HY951 10 to $12 \%$ of layer weight

- Acrylic Honeycomb of $300 * 300>>82$ grams

The Acrylic Honeycomb structure is manufactured on CNC machine by cutting the Acrylic Sheet of $2 \mathrm{~mm}$ thickness with the Hexagonal shapes of $10 \mathrm{~mm}$ size and $3.1 \mathrm{~mm}$ of wall thickness.

Figure 5 shows the $\mathrm{CNC}$ machining process should be carried at an optimum temperature so that the Acrylic material doesn't melt during the procedure. Material removed from the Acrylic sheet should be removed properly so that the edges of the hexagonal shape are not disturbed and are intact with the expected thickness and size. 
Figure 6 shows the composite material is fabricated by using hand layup technique with a mixing ratio of resin (epoxy) and hardener is 10:1. The mould surface is cleaned with Acetone and thereafter the releasing agent (wax) is applied. A thin layer of epoxy resin that is selected for the manufacturing process is applied on the mould. The glass fiber sheets and carbon fiber sheets have an aerial density of 420 G.S.M. The glass fiber reinforced polymer sheets are then completely filled with epoxy resin and rolled to squeeze the entrapped air and to uniformly spread the mixture. In this way the layers of glass fiber reinforced polymer sheets are placed one over the other to obtain the required thickness of the glass fiber face sheet. Now place the Acrylic honeycomb structure on the glass fiber sheet formed. Now on top of the Acrylic honeycomb, Similar to the glass fiber face sheet the carbon fiber reinforced polymer sheets are placed and carbon fiber face sheet is formed. Now a load of around 10 kilograms is applied for a curing period of 9-10 hours on the mould. This gives the required composite laminates which can be made to required size by cutting the sides. Sandwich with honeycomb structure with CFRP on one side and GFRP on other side of size $300 \times 300$ x 4 mm are manufactured by using hand lay-up technique.

Figure 7 shows Glass - Glass - Acrylic - Carbon - Carbon Layers >> 369.1 gms
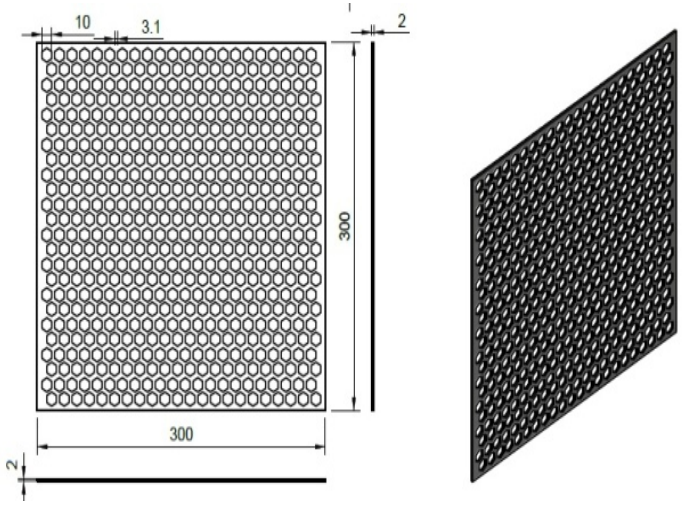

Figure 5

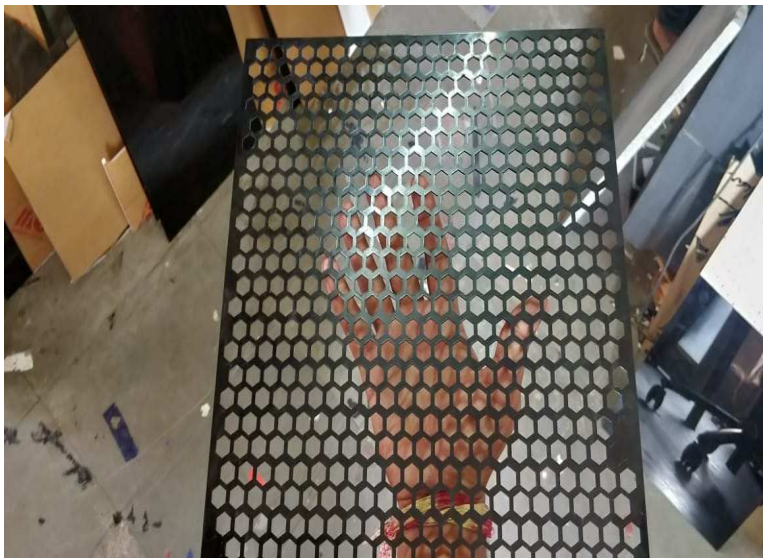

Figure 6 


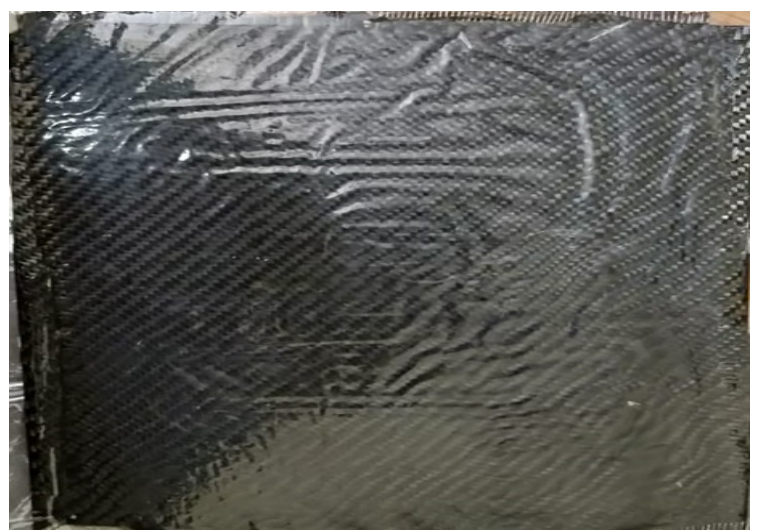

Figure 7: Weight of the Laminate after

Fabrication.

\section{TESTING RESULTS}

\subsection{Tensile Strength}

Figure 8 shows the tensile tests are performed to check for the capacity to with-stand elongation in a composite material on a universal testing machine according to ASTM D3039. The test specimen was placed between the two holders of the machine. The constant rate of loading of $4 \mathrm{~mm}$ is applied on the specimen. The specimen of $165 \mathrm{~mm}$ gauge length, $19 \mathrm{~mm}$ wide and $4 \mathrm{~mm}$ thickness is used. The values are taken from an average of 3 specimens for each honeycomb sandwich composite material. From the observations it is evident that the tensile of the sandwich composite is increased to value on an average.

\section{Tensile Specimen}

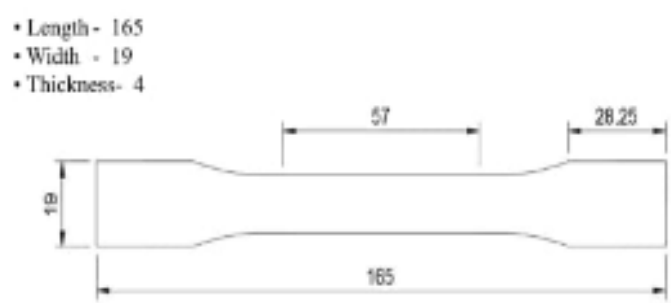

Figure 8

Table 1

\begin{tabular}{|l|c|c|c|}
\hline \multicolumn{1}{|c|}{ Ref. Standard } & \multicolumn{3}{c|}{ ASTM 3039 } \\
\hline \multicolumn{1}{|c|}{ Specimen Code } & CC-A-GG-01 & CC-A-GG-02 & CC-A-GG-03 \\
\hline Grip Length & 60 & 60 & 60 \\
\hline Guage Length & 60 & 60 & 60 \\
\hline Sample Width & 13.36 & 13.48 & 13.58 \\
\hline Sample Thickness & 3.97 & 4.43 & 4.1 \\
\hline Speed of testing (mm / min) & 5 & 5 & 5 \\
\hline Area $\left(\mathrm{mm}^{2}\right)$ & 53.0392 & 59.7164 & 55.678 \\
\hline Yield Force $(\mathrm{N})$ & 7478.75 & 6441.55 & 6017.29 \\
\hline Yield Elongation $(\mathrm{mm})$ & 8.91 & 7.23 & 6.86 \\
\hline Break Force $(\mathrm{N})$ & 8091.6 & 7054.4 & 7227.2 \\
\hline Break Elongation $(\mathrm{mm})$ & 9.48 & 7.76 & 7.74 \\
\hline Tensile Strength at Yield $\left(\mathrm{N} / \mathrm{mm}^{2}\right)$ & 141 & 107.87 & 108.07 \\
\hline Tensile Strength at Break $\left(\mathrm{N} / \mathrm{mm}^{2}\right)$ & 152.56 & 118.13 & 129.8 \\
\hline
\end{tabular}




\begin{tabular}{|l|c|c|c|}
\hline Tensile Strength at Max $\left(\mathrm{N} / \mathrm{mm}^{2}\right)$ & 153.24 & 118.5 & 131.22 \\
\hline \% Elongation $(\%)$ & 15.81 & 12.93 & 12.89 \\
\hline Max Force $(\mathrm{N})$ & 8127.62 & 7076.48 & 7305.81 \\
\hline Max Elongation $(\mathrm{mm})$ & 9.48 & 7.76 & 7.74 \\
\hline Modulus of Elasticity $\left(\mathrm{N} / \mathrm{mm}^{2}\right)$ & 1110.04 & 1092.28 & 1116.26 \\
\hline
\end{tabular}
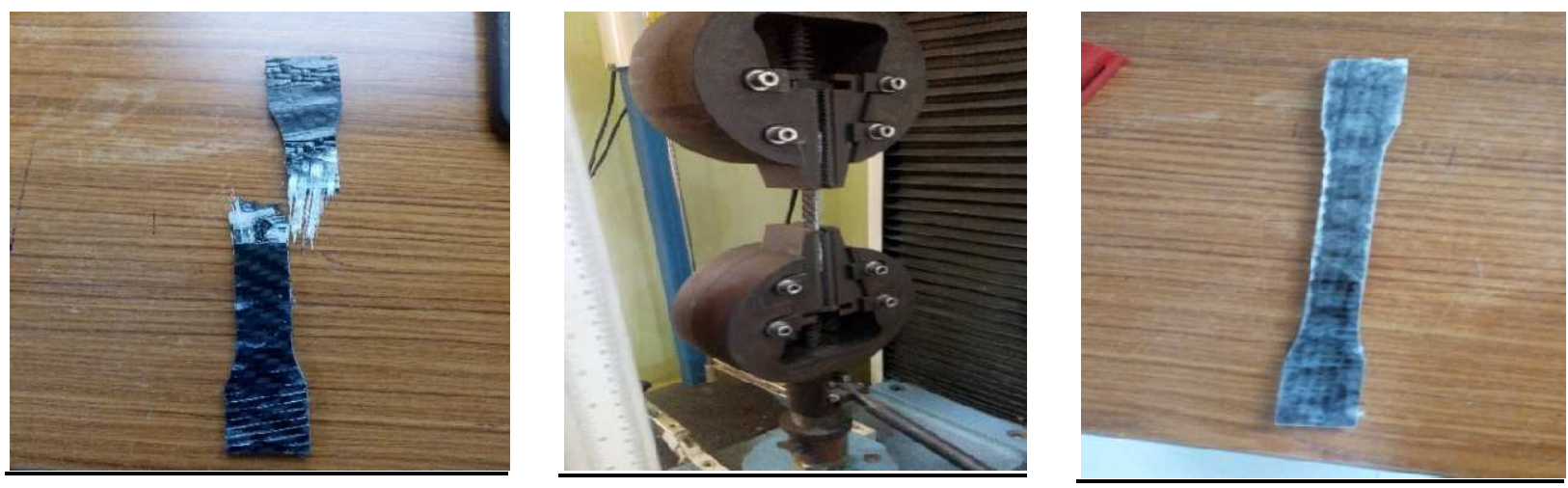

Figure 9

4.1.1. Tensile Strength CC-A-GG01

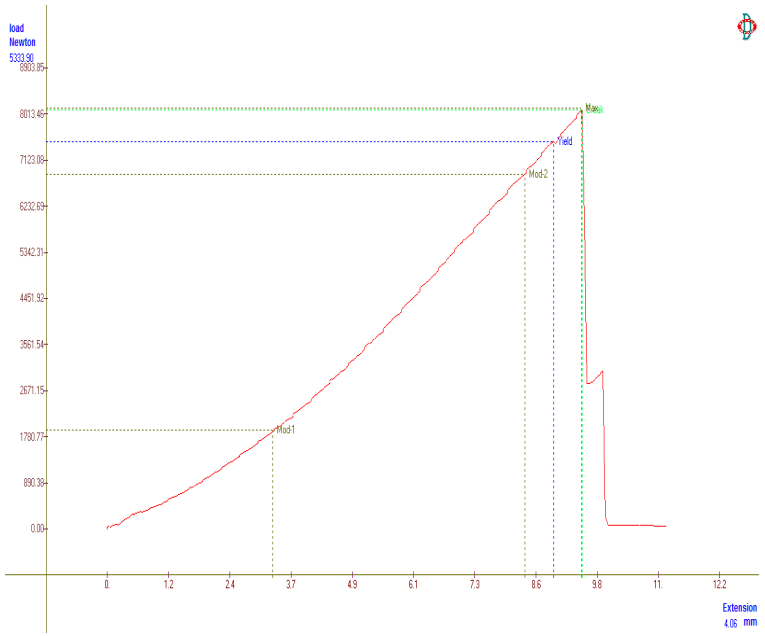

Figure 10

\subsubsection{Tensile Strength CC-A-GG02}

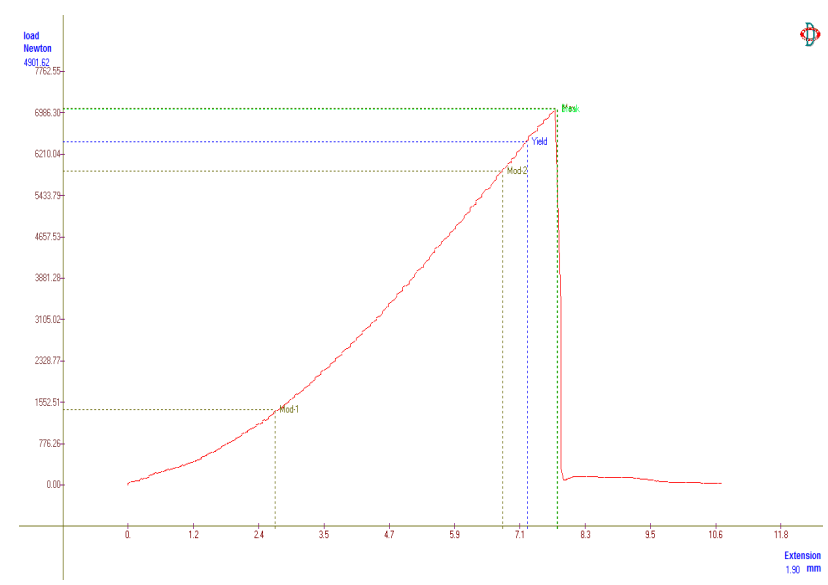

Figure 11 


\subsubsection{Tensile Strength CC-A-GG03}

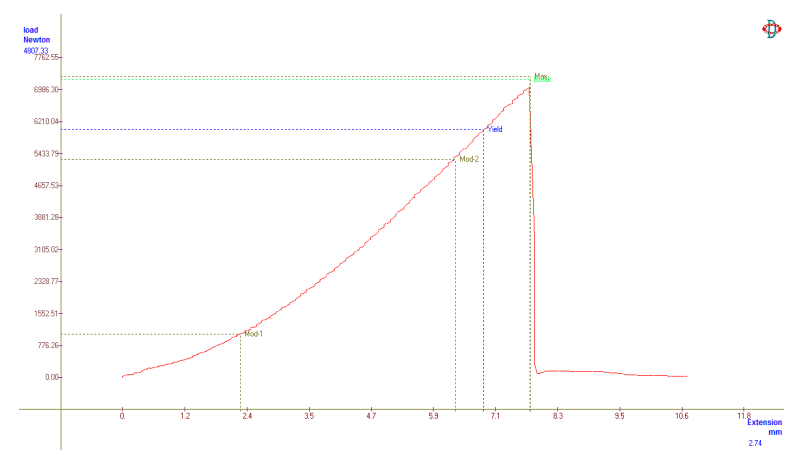

Figure 12

\subsection{Flexural Strength}

Flexural tests areconducted to check for Composite material properties against the bending forces with rectangular samples according to ASTM D-790 using a universal testing machine, fitted with a three-point bending fixture at a cross-head with a speed of $2 \mathrm{~mm} / \mathrm{min}$. In this system, a centre loading is utilised on a simply supported beam. The values are taken from an average of 3 specimens for each composite and each composition.

\section{Flexural Specimen}

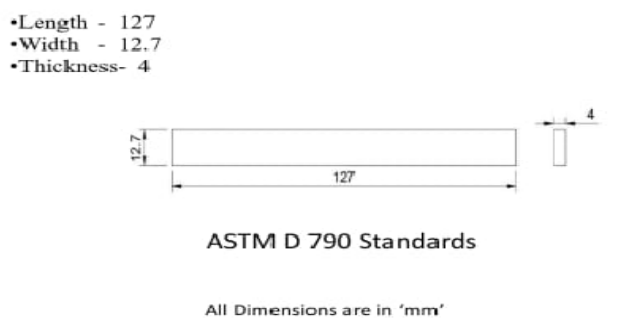

Figure 13
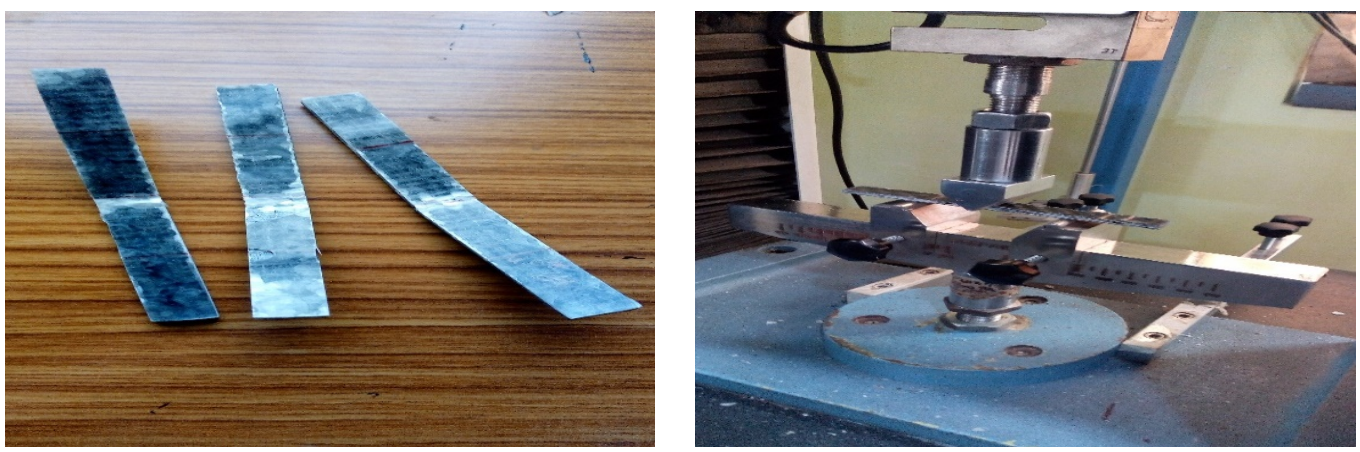

Figure 14

Table 2

\begin{tabular}{|l|c|c|c|}
\hline \multicolumn{1}{|c|}{ Ref. Standard } & \multicolumn{3}{c|}{ ASTM D790 } \\
\hline \multicolumn{1}{|c|}{ Specimen Code } & CC-A-GG-01 & CC-A-GG-02 & CC-A-GG-03 \\
\hline Span Length & 64 & 64 & 64 \\
\hline Sample Width & 13.34 & 13.34 & 13.34 \\
\hline Sample Thickness & 4.07 & 4.16 & 4.16 \\
\hline Speed of testing (mm/min) & 5 & 5 & 5 \\
\hline Area $\left(\mathrm{mm}^{2}\right)$ & 54.2938 & 55.4944 & 55.4944 \\
\hline
\end{tabular}




\begin{tabular}{|l|c|c|c|}
\hline Yield Force $(\mathrm{N})$ & 487.2154414 & 393.381 & 326.673 \\
\hline Yield Deflection $(\mathrm{mm})$ & 4.22 & 3.49 & 2.75 \\
\hline Max Force $(\mathrm{N})$ & 560.9 & 459.9 & 409.9 \\
\hline Max Deflection $(\mathrm{mm})$ & 5 & 5 & 4 \\
\hline Flexural Strength @ Yield $\left(\mathrm{N} / \mathrm{mm}^{2}\right)$ & 64.58 & 51.01 & 42.36 \\
\hline Flexural Strength @ Max $(\mathrm{MPa})$ & 243.6931319 & 191.2591672 & 170.4612621 \\
\hline Flexural Strain & 0.02992156 & 0.030596161 & 0.024308097 \\
\hline Flexural Modulus at 1\% Strain $(\mathrm{MPa})$ & 40874.98 & 31386.12 & 27973.13 \\
\hline Flexural Modulus of elasticity $\left(\mathrm{N} / \mathrm{mm}^{2}\right)$ & 5183.679797 & 3910.410106 & 3360.56505 \\
\hline
\end{tabular}

\subsubsection{Flexural Test Results CC-A-GG-01}

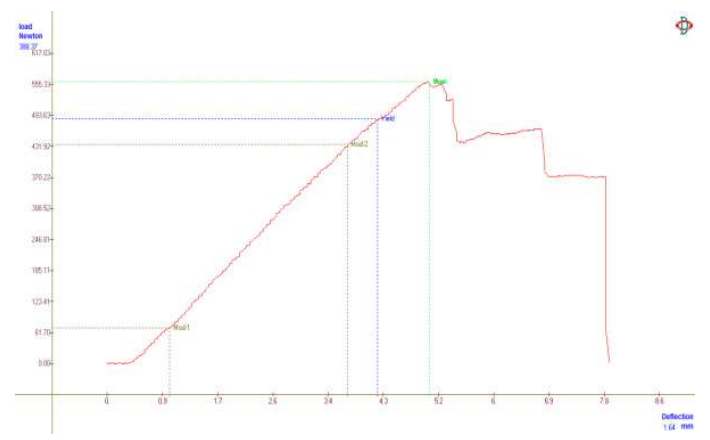

Figure 15

\subsubsection{Flexural Test Results CC-A-GG-02}

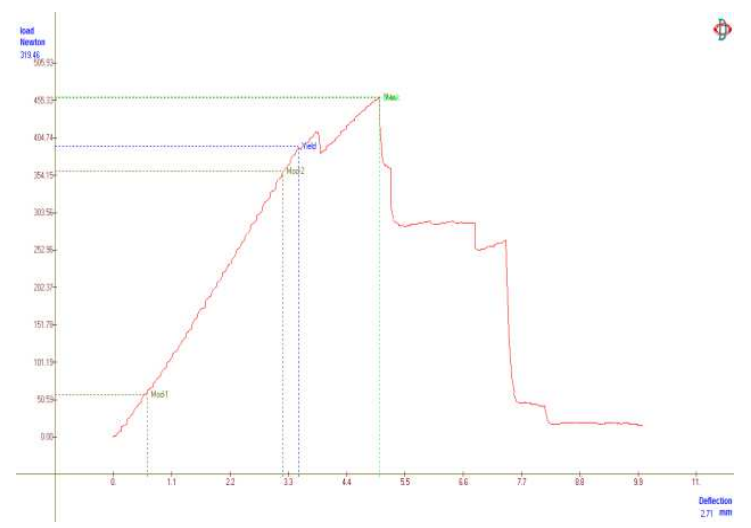

Figure 16

\subsubsection{Flexural Test Results CC-A-GG-03}

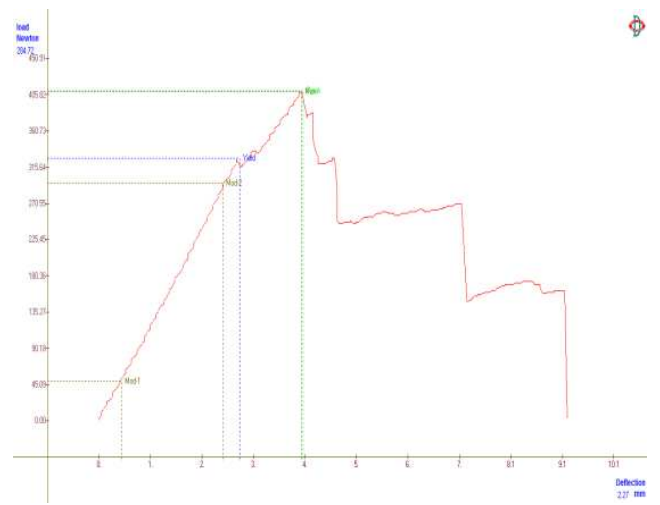

Figure 17 


\subsection{Impact Strength}

According to ASTM D256-56, composites specimens are prepared for testing the ability to withstand a given load at V notch. The specimen length of $60 \mathrm{~mm}$, thickness of $4 \mathrm{~mm}$ and the $\mathrm{V}$ notch is made at a distance of $30 \mathrm{~mm}$ from the top at a depth of $2.5 \mathrm{~mm}$ is prepared. In Izod type test the specimen is held as a cantilever beam (usually vertical) and is broken by a blow delivered at a fixed distance from the edge of the specimen clamp. The test required a notched specimen in all cases. Work-done is recorded in Joules.

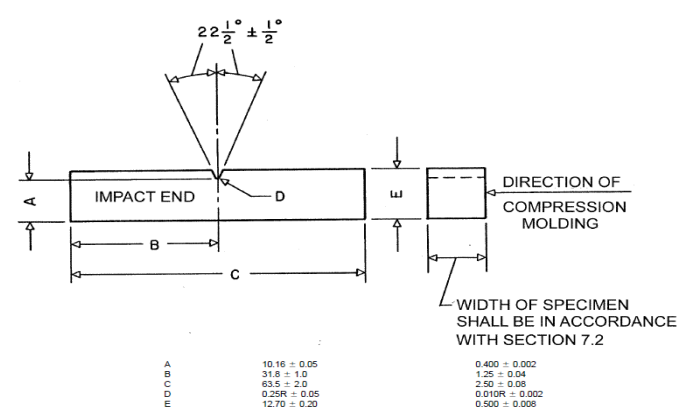

Figure 18
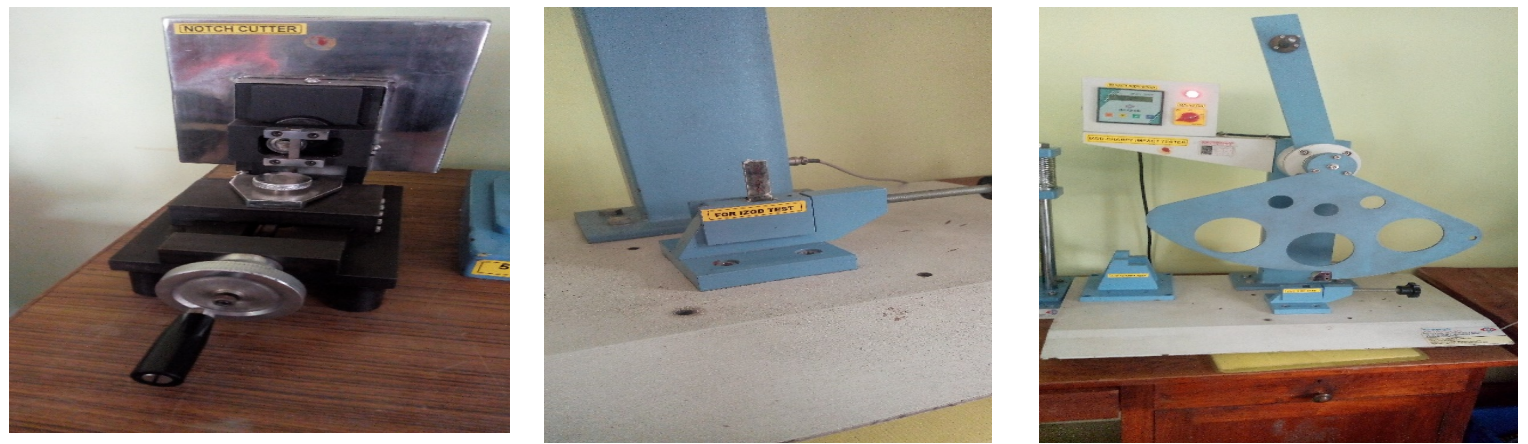

Figure 19

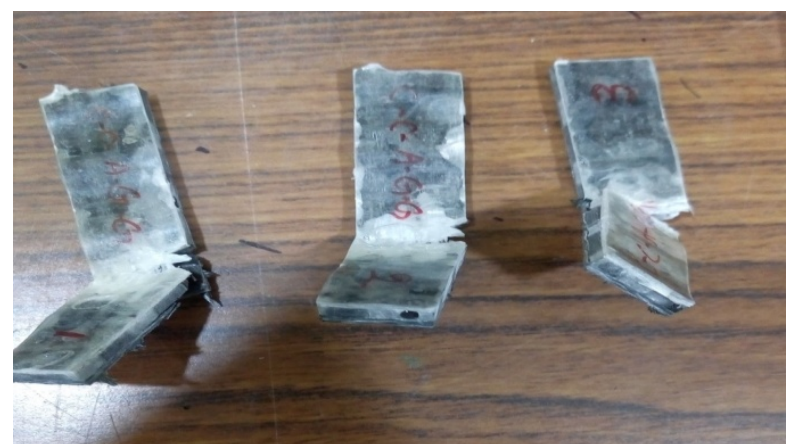

Figure 20

Table 3

\begin{tabular}{|c|c|c|c|c|c|c|}
\hline $\begin{array}{c}\text { S } \\
\text { No }\end{array}$ & Sample Id & Thickness & Width & $\begin{array}{c}\text { Work done (W / D) } \\
\text { (Joules) }\end{array}$ & $\begin{array}{c}\text { Impact Resistance } \\
\text { (Joule / m) }\end{array}$ & $\begin{array}{c}\text { Impact Strength } \\
\text { (KJ / m2) }\end{array}$ \\
\hline 1 & CCAGG01 & 3.64 & 13.45 & 2.853 & 212.12 & 58.27 \\
\hline 2 & CCAGG02 & 4.46 & 14.23 & 2.957 & 207.80 & 46.59 \\
\hline 3 & CCAGG03 & 3.28 & 3.28 & 2.145 & 162.01 & 49.39 \\
\hline
\end{tabular}

Impact Resistance $=$ Work done $* 1000 /$ width $($ Joule $/ \mathrm{m})$

Impact Strength $=$ Work done $* 1000 /$ (thickness $*$ width $)(\mathrm{KJ} / \mathrm{m} 2)$ 


\subsection{Hardness Test}

The Hardness test is performed in a Barcol Hardness testing machine according to ASTM - D 2583. This method is most often used for composite material such as reinforced thermosetting resins or to determine how much resin or plastic has cured. The hardness is measured based on reading from the indentation of a sharp point with a flat tip. The Barcol hardness is measured on a scale from 0 to 100 .

Table 4

\begin{tabular}{|c|c|c|c|c|c|c|c|}
\hline $\begin{array}{c}\text { S } \\
\text { No }\end{array}$ & Sample & $\begin{array}{c}\text { Hardness } \\
\text { Iteration 1 }\end{array}$ & $\begin{array}{c}\text { Hardness } \\
\text { Iteration 2 }\end{array}$ & $\begin{array}{c}\text { Hardness } \\
\text { Iteration 3 }\end{array}$ & $\begin{array}{c}\text { Hardness } \\
\text { Iteration 4 }\end{array}$ & $\begin{array}{c}\text { Hardness } \\
\text { Iteration 5 }\end{array}$ & Average \\
\hline 1 & CCAGG & 39 & 29 & 38 & 50 & 45 & 40.2 \\
\hline
\end{tabular}

\subsection{SEM Test}

Scanning Electron Microscopy (SEM) is a test process that scans a sample with an electron beam to produce a magnified image for analysis. The method is additionally referred to as SEM analysis or SEM microscopy and is employed very effectively in microanalysis and failure analysis of solid inorganic materials. Electron microscopy is carried out or processed at very high magnifications, generates high-resolution images, and precisely measures very small features and objects.

Scanning microscopy uses a focused beam of high-energy electrons to get a spread of signals at the surface of solid specimens. In most SEM microscopy applications, data is collected over a specific area of the surface of the sample and a two-dimensional image is generated that displays spatial variations in properties which includes chemical characterization, texture, and orientation of materials. The SEM is additionally capable of performing analyses of selected point locations on the sample. This approach is particularly useful in qualitatively or semi-quantitatively determining chemical compositions, crystalline structure, and crystal orientations.

The EDS detector separates the characteristic X-rays of various elements into an energy spectrum and EDS system software is employed to research the energy spectrum so as to work out the abundance of specific elements. A typical EDS spectrum is displayed as a plot of X-ray counts vs. energy (in keV). Energy peaks correspond to the varied elements within the sample. Energy Dispersive X-ray Spectroscopy are often wont to find the chemical composition of materials right down to a spot size of a couple of microns and to make element composition maps over a much broader raster area. Together, these capabilities provide fundamental compositional information for a wide variety of materials, including polymers and metals.

\section{RESULTS OF SEM TESTS}
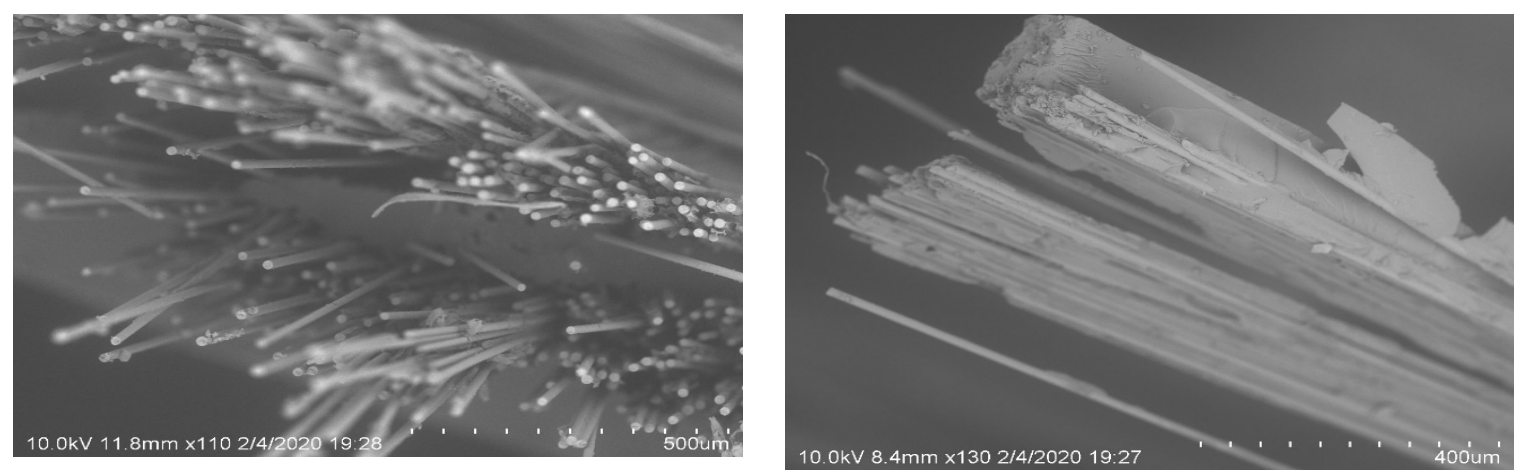

Figure 21 

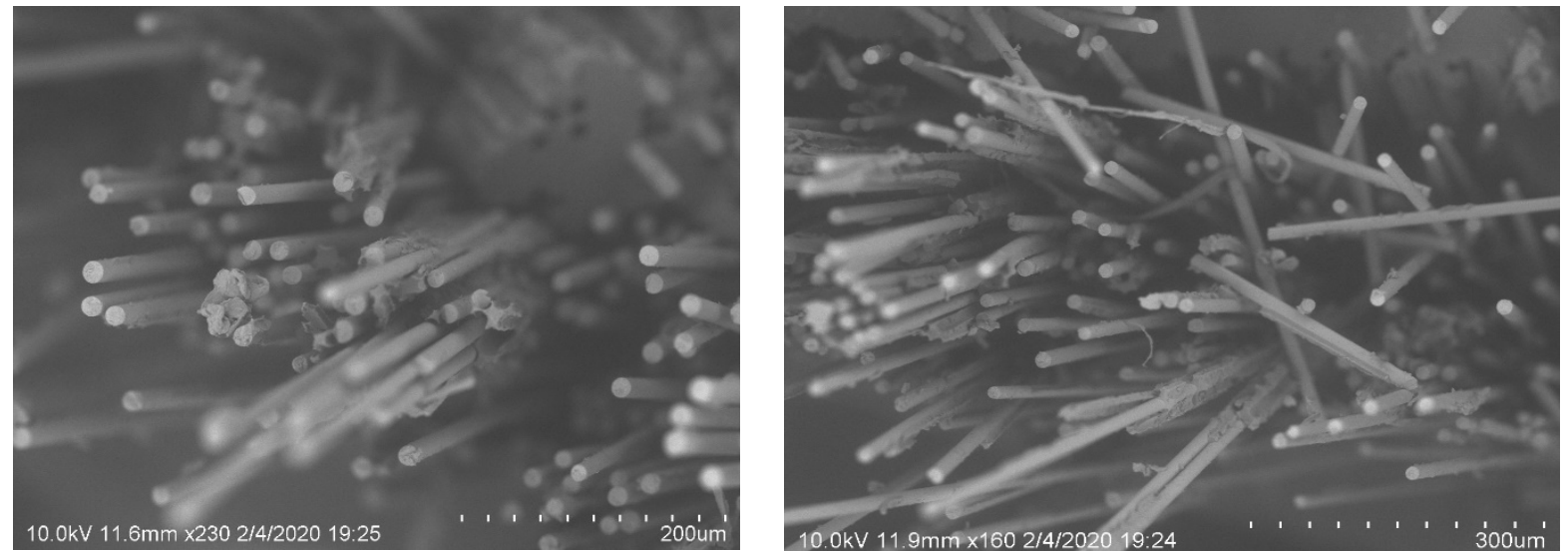

Figure 22

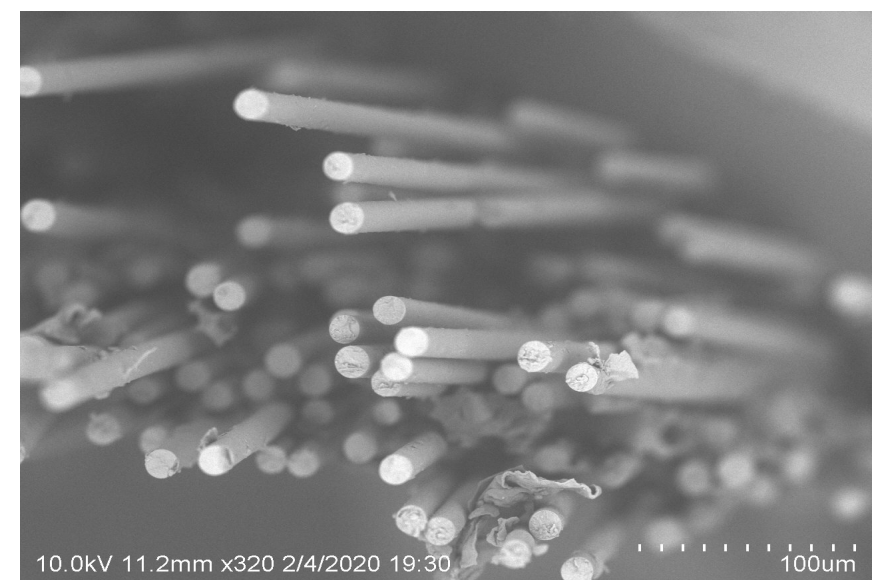

Figure 23

\section{CONCLUSIONS}

In this paper, Composite Material with Carbon fiber Reinforced Polymer(CFRP), Acrylic and Glass fiber Reinforced Polymers (GFRP), Their Mechanical Properties such as Tensile Strength, Flexural Strength, Impact Strength, Hardness and SEM are tested and results are drafted to tables for 3 specimens, The Following Conclusions are drawn.

- Tensile Tests on the CC-A-GG specimens are exhibiting an average "elongation" of 8.32 mm and an average "Tensile Strength at Break" of $133.49 \mathrm{~N} / \mathrm{mm}^{2}$

- Flexural Tests on the CC-A-GG specimens are exhibiting an average "Flexural Strength @ Max" of 201.80 MPa

- Impact Tests on the CC-A-GG specimens are exhibiting an average "Impact Strength" of $51.41 \mathrm{KJ} / \mathrm{m}^{2}$

- Hardness Tests on the CC-A-GG specimens are exhibiting an average "Barcol Hardness" of 40.2 which is measured on scale of 0 to 100

- SEM Analysis is done on the specimens used in above tests on the surfaces, where they are broken and destroyed during the tests

From the above experimental data, it can be concluded that the Composite Material formed by Carbon fiber Reinforced Polymer(CFRP) and Glass fiber Reinforced Polymers (GFRP) along with Acrylic Honeycomb exhibits more strength in almost all the mechanical properties. 


\section{REFERENCES}

1. Komal A. Jangavali, D. P. Kamble, Finite element analysis and experimental evolution of Honeycomb Panel, International Journal of Science and Research, 5 (9), 2016, 10701073.

2. M. Bharath Kumar, V. Diwakar Reddy, Design and Fabrication of Tubular Cored Sandwich Panels under Three-Point Bending, International Journal of Emerging Technologies in Engineering Research, 6 (3), 2018, 3643.

3. Al-Shammari, Mohsin Abdullah, and M. U. H. A. N. N. A. D. Al-Waily. "Analytical investigation of buckling behaviour of honeycombs sandwich combined plate structure." International Journal of Mechanical and Production Engineering Research and Development (IJMPERD) 8.04 (2018): 771786.

4. Satya Kiran O. N. V, A. Gopichand, Mahesh Krishna B, P S N Raju, Impact and Strength Analysis of All-Steel Sandwich Structures for Different Core Shapes, International Journal of Engineering Trends and Technology, 32(2), 2016, 106112.

5. Dipak G. Vamja, G. G. Tejani, Experimental Test on Sandwich Panel Composite Material, International Journal of Innovative Research in Science, Engineering and Technology, 2(7), 2013, 30473054.

6. F. Ernesto Penado, Effective Elastic Properties of Honeycomb Core with Fiber-Reinforced Composite Cells, Journal of Composite Materials, 3, 2013, 8996.

7. Maythraza, M., et al. "Vibration analysis of honeycomb sandwich panel in spacecraft structure." International Journal of Mechanical and Production Engineering Research and Development 8.3 (2018): 849860.

8. K.Kantha Rao, K. Jayathirtha Rao A.G.Sarwade, M.Sarath Chandra, Strength Analysis on Honeycomb Sandwich Panels of different Materials, International Journal of Engineering Research and Applications, 2(3), 2012, 365374.

9. Yaseen, NOOR DHIA, JUMAA S. Chiad, and Firas Mohammed Abdul Ghani."The Study and Analysis of Stress Distribution Subjected on the Replacement Knee Joint Components using Photo-Elasticity and Numerical Methods." International Journal of Mechanical and Production Engineering Research and Development (IJMPERD) 8.06 (2018): 449464.

10. Ajinkay R. Bagade, Prashant M. Kulkarni, Experimental Analysis of Aluminum Honeycomb Sandwich Panel, International Journal for Scientific Research \& Development, 6(12), 2019, 226232.

11. Shaik.Nazeer, Shaik Allabakshu, Design and Analysis of Honey Comb Structures with Different Cases, International Journal of Engineering Development and Research, 3(4), 2015, 144156.

12. KUMAR, SANDEEP, and SATBIR SINGH SEHGAL."EFFICIENT SOLAR COLLECTOR MATERIAL AND WORKING." INTERNATIONAL JOURNAL 7.4 (2017): 2938.

13. Pankaj Goswami, Thermal Insulation analysis of an Aramid honeycomb Sandwich Structure Filled with Silica Aerogel, International Journal of Engineering Research in Mechanical and Civil Engineering, 3(7), 2018, 16.

14. Md. JabihullaShariff, R. Satya Meher, Design Modulation of Composite Material Sandwich Panels with Different Inner Polyethylene Core Structures, International Journal of Engineering Research \& Technology, 3(11), 2014, 404-408. 

